\title{
KUALITAS KEPEMILIKAN PENGETAHUAN SIMBOL MELAYU BIDANG PERMAINAN DI KALANGAN MAHASISWA
}

\author{
Hermandra $^{1}$, M. Nur Mustafa ${ }^{2}$, Zulhafizh $^{3}$ \\ Universitas Riau, Pekanbaru, Indonesia ${ }^{1,2,3}$ \\ hermandra@lecturer.unri.ac.id ${ }^{1}, \underline{\text { m.nur@lecturer.unri.ac.id }{ }^{2}, z u l h a f i z h @ l e c t u r e r . u n r i . a c . i d^{3}}$
}

\begin{abstract}
This research was motivated by technological advances that have influenced traditional games' popularity as symbols of culture, so it is necessary to preserve and maintain them through the quality of knowledge. How can the quality of possession of knowledge of Malay symbols in the field of play among FKIP Riau University students be formulated? The research objective was to analyze and describe the quality of possession of knowledge of Malay symbols in the field of play among FKIP students at the University of Riau. This research used a descriptive quantitative approachobservation of knowledge with a likert scale. The observation sample was 870 people from a population of 6300 people or $13.8 \%$ of $100 \%$. The sample was taken randomly based on questionnaire filling and collection. The technique of collecting data employed a questionnaire related to the traditional games of the Riau Malay community. The process of collecting data distributed through $a$ google form. The collected data were substituted and analyzed with descriptive statistics, Product Moment, and Anova. The analysis results showed that students' knowledge regarding traditional games of the Malay community as a cultural symbol was at a standard of mean 4.37 with a very high category. The games of gasing, bakiak, congkak, enggrang, layang-layang, tarik tambang, petak umpet, benteng, ligu, and statak can contribute information to knowledge ownership of the games of the Riau Malay community by $35.9 \%$. In comparison, other games were at $64.1 \%$. The possession of this knowledge has supported documenting various games and preserving the existence of these games. Besides, the content of values in the game is a means of character education and supports learning and learning activities.

Keywords: quality, knowledge, games, Malay
\end{abstract}

\section{ABSTRAK}

Penelitian ini dilatarbelakangi oleh kemajuan teknologi turut memengaruhi popularitas permainan tradisional sebagai simbol kebudayaan, maka perlu melestasikan dan menjaganya melalui kualitas pengetahuan. Dasar tersebut dapat dirumuskan bagaimana kualitas kepemilikan pengetahuan simbol Melayu bidang permainan di kalangan mahasiswa FKIP Universitas Riau? Tujuan penelitian menganalisis dan mendeskripsikan kualitas kepemilikan pengetahuan simbol Melayu bidang permainan di kalangan mahasiswa FKIP Universitas Riau. Penelitian menggunakan pendekatan kuantitatif deskriptif. Pengamatan pengetahuan dengan Skala Likert. Sampel pengamatan 870 orang dari populasi 6300 orang atau 13,8\% dari 100\%. Sampel diambil secara random berdasarkan isian dan pengumpulan angket. Teknik pengumpulan data dengan angket yang berkaitan dengan permainan tradisonal masyarakat Melayu Riau. Proses pengumpulan data dengan memanfaatkan google form. Data yang terkumpul disubsitusikan dan dianalisis dengan statistik deskriptif, Product Moment, dan Anova. Hasil analisis memperlihatkan pengetahuan yang dimiliki mahasiswa terkait permainan tradisional masyarakat Melayu sebagai simbol budaya berada pada standar mean 4,37 dengan kategori sangat tinggi. Permainan gasing, bakiak, congkak, enggrang, layang-layang, tarik tambang, petak umpet, benteng, ligu, dan statak mampu memberikan sumbangan informasi terhadap kepemilikan pengetahuan terhadap permainan masyarakat Melayu Riau sebesar 35,9\% sedangkan $64,1 \%$ ditentukan oleh permainan lainnya. Kepemilikan pengetahuan tersebut telah menunjang pendokumentasian ragam permainan juga melestarikan keberadaan permainan tersebut. Selain itu, kandungan nilai-nilai dalam permainan menjadi sarana pendidikan karakter dan penunjang kegiatan belajar dan pembelajaran.

Kata Kunci: kualitas, pengetahuan, permainan, Melayu

Kualitas Kepemilikan Pengetahuan Simbol Melayu Bidang Permainan di Kalangan Mahasiswa 


\section{PENDAHULUAN}

Permainan kerakyatan merupakan suatu bentuk menginformasikan keberagaman budaya, terutama terkait suku yang ada ditempat tersebut. Keberadaan permainan tersebut penting diketahui dan dikenali oleh masyarakat secara umum dan khususnya di kalangan mahasiswa. Hal ini mengingat bahwa masyarakat maupun mahasiswa salah satu penggerak berbagai kegiatan yang diselenggarakan dalam kehidupan sosial. Pada konteks ini, mahasiswa harus memiliki pengetahuan terhadap permainan yang dimasukkan dalam sesi kegiatan yang diselenggarakan.

Adanya pengetahuan terhadap ragam permainan memungkinkan untuk mengisi acara, maka permainan tersebut bisa ditempatkan sejalan dengan tema kegiatan. Artinya, permainan yang dihadirkan tidak hanya hiburan atau sosialisasi saja, tetapi beririsan dengan tujuan kegiatan. Hal ini mampu memperkuat kebermaknaan kegiatan yang diselenggarakan. Untuk itu, mahasiswa harus memiliki pengetahuan terhadap ragam permainan yang ada sehingga dapat mempersiapkan berbagai kebutuhan yang diperlukan.

Pengetahuan yang kurang memadai tentu dapat menyulitkan dalam membuat persiapan-persiapan yang diperlukan. Artinya setiap penyelengaraan suatu permainan memerlukan pengetahuan yang baik agar dapat menghadirkan makna yang benar dan tepat, baik berkaitan dengan bentuk dan prosedurnya. Seperti halnya permainan egrang dalam masyarakat Melayu. Permainan ini memiliki bentuk yang beragam dan ada teknis menggunakannya. Penyelenggaran dan pemainnya harus memahami bentuk, ukuran, dan teknis memainkan egrang agar dapat memberikan nilai atau makna. Berkaitan dengan permainan tersebut, maka isu pengetahuan mahasiswa menjadi dasar dilakukan pengamatan terhadap Kualitas Kepemilikan Pengetahuan Simbol Melayu bidang Permainan di Kalangan Mahasiswa FKIP Universitas Riau.

Di tengah kemajuan teknologi, permainan rakyat Melayu sangat memungkinkan tergeser popularitasnya mengingat sudah banyaknya tersedia permainan elektronik. Anak-anak masa kini bisa dikatakan asing, bahkan tidak tahu lagi tentang permainan nenek moyang mereka itu, apalagi tentang makna dan filosofi dalam permaianan tersebut (Susanti, Siswati, \& Widodo, 2010:151). Untuk itu, penting bagi masyarakat Melayu, khususnya Riau maupun lembaga terkait seperti FKIP dalam melestarikan permainan tersebut, baik dengan cara menggelar lomba atau sekadar pertunjukan biasa. FKIP Universitas Riau merupakan salah satu lembaga yang konsen dalam memberikan edukasi kepada mahasiswa tentang kehidupan sosial dan budaya Melayu. FKIP memiliki peran dalam menjaga dan melestarikan permainan Melayu Riau dan nilainilai yang terkandung di dalamnya.

Dalam kehidupan sosial Melayu Riau, permainan rakyat atau tradisional penting dipahami. Dalam setiap permainan mengandung filosofi atau tunjuk ajar. Permainan tradisional merupakan simbolisasi dari pengetahuan yang mempunyai bermacam-macam fungsi, manfaat atau pesan (Andriani, 2012:122). Permainan rakyat dapat memengaruhi perkembangan anak berkaitan dengan kecerdasan intelektual, mengembangkan kecerdasan emosi, mengembangkan daya kreativitas, meningkatkan kemampuan bersosialisasi serta dapat melatih kemampuan motorik (Rahayu, Hamid, \& Sutini, 2018:66). Penjelasan tersebut memberikan petunjuk bahwa permainan Melayu memiliki nilai edukasi yang mampu menstimulus kognitif, psikomotorik, dan afektif para pemainnya.

Secara umum, permainan-permainan tradisional yang berasal dari Riau dapat dikelompokkan menjadi dua bagian, yaitu: yang dimainkan dalam ruangan dan diluar ruangan. Permainan di dalam ruangan (indoor) terdiri atas permainan congklak, gasing, statak, petak umpet, benteng dan biji karet. Sementara itu, jenis permainan yang berada di luar ruangan (outdoor) seperti: lulu cina buta, bakiak, engrang, layang-layang, tarik tambang, kelereng dan ligu (Ningsih, Firzal, \& Aldy, 2020:220). Permainan tersebut juga dapat dikelompokkan berdasarkan tempat dan waktu bermain serta alat yang digunakan (Rasyid, Saman, \& Syahrani, 2016:76)

Sebagai unsur budaya, permainan tradisonal masyarakat Melayu ini penting

Kualitas Kepemilikan Pengetahuan Simbol Melayu Bidang Permainan di Kalangan Mahasiswa 
diketahui dan dipahami agar keberadaan tidak hilang. Permainan tradisional atau rakyat sebagai satu di antara unsur kebudayaan bangsa perlu diselamatkan dan dilestarikan (Purwaningsih, 2006:45). Sebuah usaha yang dapat dilakukan adalah mempelajarinya, mendokumentasikan, dan memainkannya. Di era digital permainan dapat dimuat dalam bentuk aplikasi (Atan, Indra, \& Febriko, 2020:66; Candra \& Wahyudi, 2015:1). Akan tetapi, nilai-nilai filosofisnya tidak bisa dirasa dan didapat secara maksimal oleh pemain jika tidak dilakukan secara langsung. Untuk itu permainan tradisional-Melayu mesti dikenal dan diperkenalkan (Bastian, Suharni, \& Novitasari, 2019:53; Syaharuddin, Pramita, \& Sirajuddin, 2019:2; Nadjamuddin, 2016:77). Jika hal ini tidak dilakukan maka permainan tradisional bisa tergeser oleh perkembangan global yang terus menghadirkan berbagai permainan elektronik modern.

Berdasarkan paparan tersebut, permainan rakyat atau tradisional tidak hanya sebagai hiburan, tetapi sebagai edukasi, serta perlu dilestarikan agar tidak musnah. Berdasar hal tersebut memperkuat dilakukan pengamatan terhadap kualitas pengetahuan simbol Melayu sebagai bidang permainan di kalangan Mahasiswa FKIP Universitas Riau. Tujuan pengamatan tersebut untuk mendeskripsikan mendeskripsikan kualitas pengetahuan mahasiswa terkait dengan permainan tradisonal masyarakat Melayu.

\section{METODOLOGI PENELITIAN}

Penelitian dilakukan dengan pendekatan kuantitatif deskriptif. Dasar pendeskripsian bertolok pada instrumen yang digunakan untuk pengumpulan data yaitu berupa angket. Intrumen berkaitan dengan permainan tradisonal masyarakat Melayu Riau yang terdiri 10 ragam permainan. Pengetahuan terhadap permainan tradisional ini diamati dengan Skala Likert yang terdiri dari lima opsi jawaban atau tanggapan. Instrumen atau angket sebarkan kepada mahasiswa FKIP Universitas Riau dengan jumlah 870 orang atau $13,8 \%$ dari populasi 6.300 orang.

Mengingat penelitian ini pada masa pendemi covid-19 maka sampel adalah sejumlah mahasiswa yang memberikan respon.
Proses pengumpulan data dengan memanfaatkan google form. Strategi ini untuk mengefektifkan dalam pengumpulan data. Sementara itu, analisis data dengan menggunakan statistik deskriptif, Product Moment, dan Anova. Adapun keputusan rata-rata berdasarkan kriteria penilaian pada tabel 1 .

Tabel 1. Interval dan Kriteria Penilaian

\begin{tabular}{|c|c|c|c|}
\hline \multirow{2}{*}{ No. } & \multicolumn{2}{|c|}{ Skala } & \multirow{2}{*}{ Kategori } \\
\cline { 2 - 3 } & Positif & Negatif & \\
\hline 1 & $4,01-5,00$ & $2,01-1,00$ & Sangat tinggi \\
\hline 2 & $3,01-4,00$ & $3,01-2,00$ & Tinggi \\
\hline 3 & $2,01-3,00$ & $4,01-3,00$ & Rendah \\
\hline 4 & $1,00-2,00$ & $5,00-4,00$ & Sangat rendah \\
\hline
\end{tabular}

(Zulhafizh, 2020:306; Zulhafizh \& Permatasari, 2020:941)

\section{HASIL DAN PEMBAHASAN}

\section{Statistik Deskriptif}

Hasil analisis deskriptif pengetahuan permainan tradisional masyarakat Melayu dapat diamati melalui pendekatan mean dan standar, yaitu:

Tabel 2. Interpretasi Pengetahuan Permainan Tradisional Masyarakat Melayu

\begin{tabular}{|c|c|c|c|c|}
\hline No. & Indikator & Mean & SD & Kategori \\
\hline 1 & Gasing & 4,52 & 0,759 & ST \\
\hline 2 & Bakiak & 4,43 & 0,825 & ST \\
\hline 3 & Congkak & 4,60 & 0,713 & ST \\
\hline 4 & Enggrang & 4,41 & 0,810 & ST \\
\hline 5 & Layang-layang & 4,56 & 0,776 & ST \\
\hline 6 & Tarik tambang & 4,58 & 0,743 & ST \\
\hline 7 & Petak umpet & 4,49 & 0,832 & ST \\
\hline 8 & Benteng & 4,14 & 0,996 & ST \\
\hline 9 & Ligu & 3,56 & 1,136 & $\mathrm{~T}$ \\
\hline 10 & Statak & 4,08 & 1,073 & ST \\
\hline & Mean & 4,34 & 0,866 & ST \\
\hline
\end{tabular}

Ket: ST (Sangat Tinggi), T (Tinggi)

Data tabel 2 memperlihatkan bahwa pengetahuan yang dimiliki mahasiswa FKIP terkait permainan tradisional masyarakat Melayu yaitu mean 4,37 pada standar deviasi 0,866 . Pada 
kontek ini pengetahuan mahasiswa berada kategori sangat tinggi. Permainan tradisional masyarakat Melayu bisa ditemukan pada momen-momen tertentu. Tentunya masyarakat Melayu, khususnya Riau masih memainkan perannya dalam berbagai permainan karena hal ini bagian dari tradisi dan budaya. Secara rinci dapat diketahui permainan gasing berkategori sangat tinggi dengan mean 4,53 pada standar deviasi 0,759 ; permainan bakiak berkategori sangat tinggi dengan mean 4,43 pada standar deviasi 0,825 ; permainan congkak berkategori sangat tinggi dengan mean 4,60 pada standar deviasi 0,713 ; permainan enggrang berkategori sangat tinggi dengan mean 4,41 pada standar deviasi 0,810 ; permainan layang-layang berkategori sangat tinggi dengan mean 4,56 pada standar deviasi 0,776 ; permainan tarik tambang berkategori sangat tinggi dengan mean 4,58 pada standar deviasi 0,743; permainan petak umpet tambang berkategori sangat tinggi dengan mean 4,49 pada standar deviasi 0,832 ; permainan benteng tambang berkategori sangat tinggi dengan mean 4,14 pada standar deviasi 0,996; permainan ligu berkategori tinggi dengan mean 3,56 pada standar deviasi 1,136; dan permainan statak berkategori sangat tinggi dengan mean 4,08 pada standar deviasi 1,073.

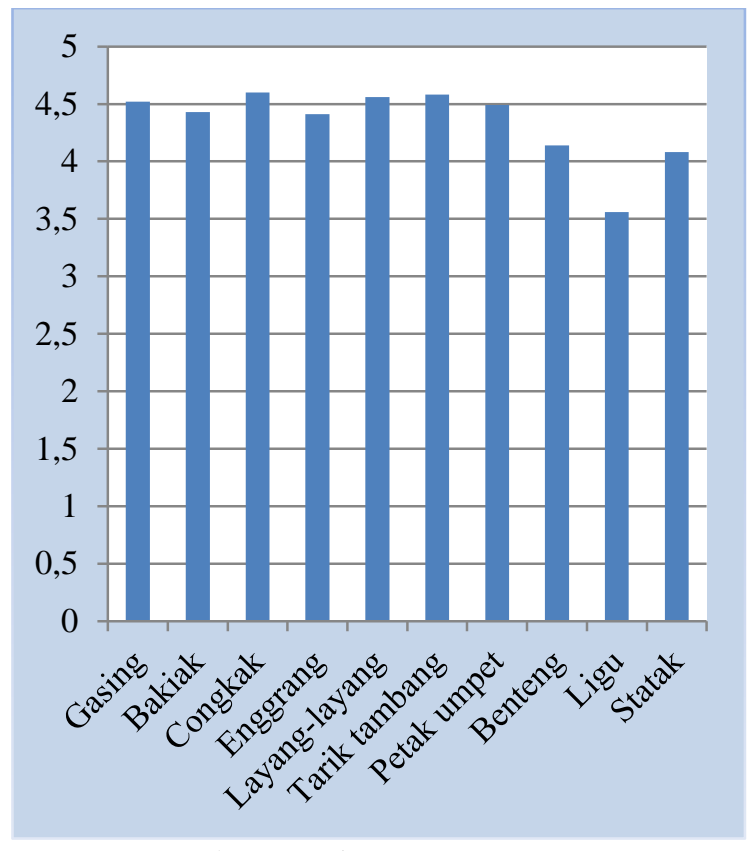

Gambar 1. Diagram Persentase

\section{Korelasi dan Normalitas Data}

Untuk memastikan adanya keterkaitan data dalam penelitian maka dilakukan analisis korelasi terhadap pengetahuan permainan tradisional masyarakat Melayu, yaitu:

Tabel 3. Korelasi Pengetahuan Permainan Tradisional Masyarakat Melayu

\begin{tabular}{|c|c|c|c|c|}
\hline No. & Indikator & Korelasi & Sig. & Kategori \\
\hline 1 & Gasing & $0,702 * *$ & 0,000 & Kuat \\
\hline 2 & Bakiak & $0,723 * *$ & 0,000 & Kuat \\
\hline 3 & Congkak & $0,717 * *$ & 0,000 & Kuat \\
\hline 4 & Enggrang & $0,677 * *$ & 0,000 & Kuat \\
\hline 5 & Layang-layang & $0,707 * *$ & 0,000 & Kuat \\
\hline 6 & Tarik tambang & $0,691 * *$ & 0,000 & Kuat \\
\hline 7 & Petak umpet & $0,697 * *$ & 0,000 & Kuat \\
\hline 8 & Benteng & $0,676 * *$ & 0,000 & Kuat \\
\hline 9 & Ligu & $0,561 * *$ & 0,000 & Kuat \\
\hline 10 & Statak & $0,640 * *$ & 0,000 & Kuat \\
\hline \multicolumn{2}{|r|}{ Mean } & $0,679 * *$ & 0,000 & Kuat \\
\hline
\end{tabular}

Secara keseluruhan data tabel 3 menunjukkan bahwa informasi permainan ini berkorelasi kuat untuk mengetahui pengetahuan mahasiswa FKIP Universitas Riau bidang permainan tradisional masyarakat Melayu. Hal ini dibuktikan dengan tingkat signifikansinya tidak melebihi 0,05. Selanjutnya, dilakukan uji normalitas data dengan uji Chi Kuadrat. Pengujian diperoleh dari perbandingan harga tidak melebih taraf signifikansi 0,05 .

Tabel 4. Uji Normalitas Data

\begin{tabular}{|c|c|c|c|c|}
\hline Pengamatan & $\mathrm{dk}$ & $\chi_{\text {hitung }}^{2}$ & Sig. & Ket. \\
\hline $\begin{array}{c}\text { Pengetahuan } \\
\text { permainan }\end{array}$ & 1 & 1134,494 & 0,000 & Normal \\
\hline
\end{tabular}

Data tabel 4 secara jelas memperlihatkan data uji normalitas tidak melebihi dari tingkat signifikansi yaitu: 0,000 $<0,05$. Nilai ini menunjukkan bahwa data informasi pengetahuan mahasiswa terkait dengan permainan tradisional masyarakat Melayu berdistribusi normal. Hal ini

Kualitas Kepemilikan Pengetahuan Simbol Melayu Bidang Permainan di Kalangan Mahasiswa 
menegaskan data tersebut dapat dianalisis dan dipertimbangkan dalam mengamati.

\section{Kontribusi Data}

Selanjut dilakukan analisis anova sederhana untuk mengetahui peranan datadata pengamatan terhadap pengetahuan permainan sebagai simbol Melayu, yaitu:

Tabel 5. Harga Peranan Data Permainan

\begin{tabular}{|c|c|c|c|}
\hline \multirow{2}{*}{ Subjek } & \multicolumn{3}{|c|}{ Harga } \\
\cline { 2 - 4 } & $\mathrm{r}_{\mathrm{xy}}$ & $\mathrm{r}_{\mathrm{xy}}{ }^{2}$ & Sig. \\
\hline $\begin{array}{c}\text { Indikator } \\
\text { Indipenden }\end{array}$ & 0,599 & 0,359 & $0,000^{\mathrm{a}}$ \\
\hline
\end{tabular}

Data tabel 5 menunjukkan bahwa data permainan seperti gasing, bakiak, congkak, enggrang, layang-layang, tarik tambang, petak umpet, benteng, ligu, dan statak mampu memberikan sumbangan informasi terhadap kepemilihan pengetahuan terhadap permainan masyarakat Melayu Riau. Hasil tafsiran memperlihatkan sumbangan sebesar 35,9\%. Sementara itu, $64,1 \%$ ditentukan oleh permainan yang lainnya.

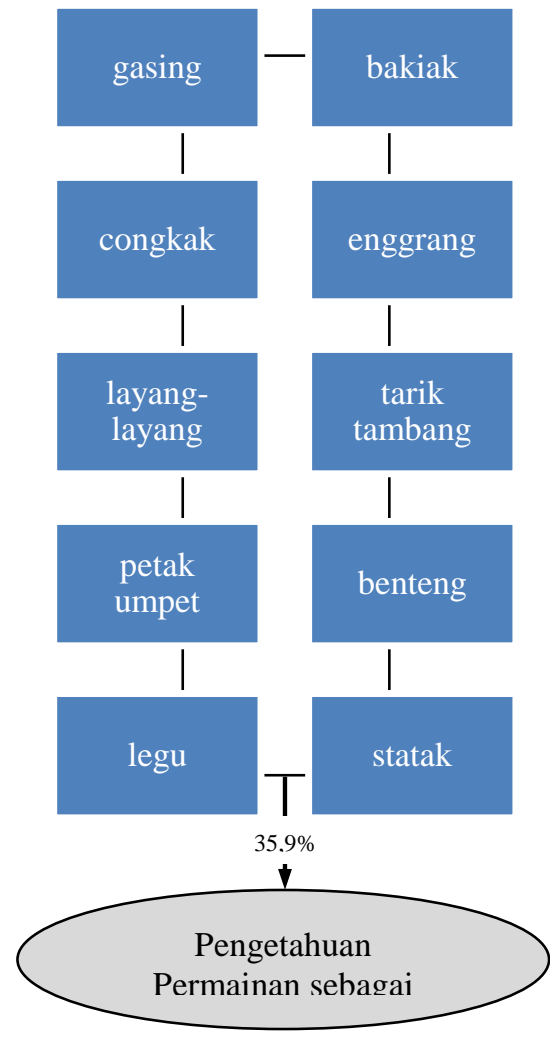

Gambar 2. Peta Kontribusi

\section{Pembahasan}

Permainan yang ada di masyarakat Melayu merupakan simbol kebudayaan. Permainan ini sebagai identitas. Sebagai masyarakat Melayu atau berada di lingkungan Melayu, khususnya Riau tentunya harus mengetahui keberagaman permainan ini. Dalam kontek sebagai mahasiswa, sangatlah penting mengetahui permainan masyarakat Melayu. Selain itu, permainan ini sebagai muatan dalam pelajaran tradisi atau budaya Melayu. Data analisis menunjukkan mahasiswa FKIP Universitas Riau sudah memiliki pengetahuan sangat baik dengan rata-rata (mean) 4,34 dengan kategori sangat baik. Walaupun demikian, kualitas pengetahuan harus ditingkan.

Informasi bentuk atau ragam permainan ini telah memberikan sumbangan pengetahuannya bidang permainan masyarakat Melayu Riau sebesar 35,9\% dan 64,1\% lagi ditentukan oleh permainan yang lainnya. Perlu adanya pengembangan pengetahuan bidang permainan sebab permainan tersebut mampu mengeksplor keberadaan masyarakat MelayuRiau (Hasanuddin, 2017:137). Sebagai generasi penerus, perlu menunjukkan permainan Melayu Riau dalam ranah yang luas karena permainan tersebut sebagai bentuk kekayaan budaya.

Zafirah et al., (2018:97) melalui penelitiannya bahwa permainan yang dimainkan bukan sekadar hiburan saja, tetapi dalam permainan tersebut mengandung berbagai nilai seperti kejujuran, disiplin, kerja keras, kreatif, rasa ingin tahu, mandiri, komunikatif, tanggung jawab dan menghargai prestasi. Hal ini dapat tunjukkan pada permainan congkak misalnya. Artinya selain sebagai simbol kebudayaan, permainan mengandung nilai-nilai yang positif. Sangat wajar para akademisi, seperti mahasiswa FKIP Universitas Riau merenungi atau merefleksikan nilai-nilai tersebut memiliki karakter. Bahkan bagi Zafirah et al., (2018:97) permainan tersebut mampu menjadi media dalam pembelajaran.

Adanya pengetahuan terhadap ragam permainan ini, khususnya pada permainan masyarakat Melayu sangat memungkinkan pelaku atau pemainnya memiliki sikap atau pribadi yang berkarakter. Dalam setiap permainan memberikan pembinaan bagi pelakunya. Murniyetti, Engkizar, \& Anwar

Kualitas Kepemilikan Pengetahuan Simbol Melayu Bidang Permainan di Kalangan Mahasiswa 
(2016:156) menjelaskan bahwa sekurangkurangnya mengerti tentang berbagai aturan, sikap menghargai, kreatif, peduli, demokratis, dan sebagainya. Jika tidak memainkan, maka bisa mengerti tentang nilai-nilai yang terkandung didalam permainan tersebut.

Sebagai mahasiswa yang kuliah bidang pendidikan dan pengajaran ini, bisa memberdayakan kandungan nilai-nilai yang terdapat dalam permainan untuk aktivitas pembelajaran (Zafirah et al., 2018:96; Darisman, 2018:2). Nilai-nilai tersebut dapat ditanamkan pada peserta didik melalui aktivitas pembelajaran (Rahayu \& Alber, 2019:92; Alber \& Andriyani, 2019:18; Ansori, 2016:29). Bekal pengetahuan tentang permainan memudahkan dalam mentransfer nilai-nilai positif tersebut melalui kegiatan belajar mengajar. Memberikan dan menanamkan nilainilai tersebut untuk memperkuat kecerdasan emosional dan kepribadian (Mulyana, 2010:7; Grier, 2012:202; Milson \& Mehlig, 2002:47). Hal ini menunjukkan betapa pentingnya sebagai mahasiswa FKIP Universitas Riau memiliki kualitas pengetahuan yang memadai tentang permainan tradisional masyarakat Melayu.

\section{SIMPULAN}

Mahasiswa FKIP sebagai penguat dalam pendidikan karakter perlu memiliki pengetahuan yang baik terhadap permainanpermainan tradisional, terutama permainan Melayu. Temuan mencatat kualitas kepemilikan pengetahuan pada permainan tradisional masyarakat Melayu berkategori tinggi dengan rata-rata (mean) 4,34 dan kontribusinya sebesar $35,9 \%$. Pengetahuan dan pemahaman permainan yang memadai dapat menjadi sarana atau media pembelajaran. Selain itu, adanya pengetahuan yang dimiliki menjadi sarana pendokumentasian ragam permainan dan budaya masyarakat-Melayu Riau. Juga, sebagai langkah untuk menjaga dan melestarikan keberadaan permainan tersebut.

\section{REFERENSI}

Alber, \& Andriyani, N. (2019). Tradisi Timang Turun Mandi pada Masyarakat Kampar: Tinjauan Nilai Budaya dan Nilai Pendidikan Karakter. Geram, 7(2), 17
29.

Retrieved

from

http://dx.doi.org/10.1016/j.cej.2014.10.020

\%0Ahttp://dx.doi.org/10.1016/j.apcatb.201

3.08.019\%0Ahttp://dx.doi.org/10.1016/j.tsf .2016 .12 .015

Andriani, T. (2012). Permainan Tradisional Dalam Membentuk Karakter Anak Usia Dini. Jurnal Sosial Budaya, 9(1), 121-136.

Ansori, R. A. M. (2016). Strategi Penanaman Nilai-Nilai Pendidikan Islam Pada Peserta Didik. Jurnal Pusaka: Media Kajian Dan Pemikiran Islam, 8, 14-32.

Atan, A., Indra, Z., \& Febtriko, A. (2020). Perancangan Game Berbasis Android untuk Memperkenalkan Adat Melayu Riau. RABIT: Jurnal Teknologi Dan Sistem Informasi Univrab, 5(1), 54-66.

Bastian, A., Suharni, \& Novitasari, Y. (2019). Permainan Tradisional Berbasis Budaya Melayu dalam Pengembangan Karakter Anak. Atfāalunā: Journal of Islamic Early Childhood Education, 2(2), 53-56. https://doi.org/10.32505/atfaluna.v2i2.974

Agustina, C., \& Wahyudi, T. (2015). Aplikasi Game Pendidikan Berbasis Android Untuk Memperkenalkan Pakaian Adat Indonesia. IJSE - Indonesian Journal on Software Enginee, $1(1), \quad 1-8$. https://doi.org/10.16429/j.10097848.2015.05.005

Darisman, D. (2018). Nilai-Nilai Pendidikan Akhlak. Tarbiyah al-Aulad, 3(2), 1-16.

Grier, L. K. (2012). Character, SocialEmotional, and Academic Outcomes Among Underachieving Elementary School Students. Journal of Education for Students Placed at Risk (JESPAR), 17(3), 201-216.

Hasanuddin. (2017). Etnomatematika Melayu: Pertautan antara Matematika dan Budaya pada Masyarakat Melayu Riau. Sosial Budaya, 14(2), 136-149.

Milson, A. J., \& Mehlig, L. M. (2002). Elementary School Teachers' Sense of Efficacy for Character Education. The Journal of Educational Research, 96(1), 47-53.

Mulyana, E. H. (2010). Guru Berkualitas: Profesional dan Cerdas Emosi. Jurnal Saung Guru, 1(2), 1-11.

Kualitas Kepemilikan Pengetahuan Simbol Melayu Bidang Permainan di Kalangan Mahasiswa 
Murniyetti, M., Engkizar, E., \& Anwar, F. (2016). Pola Pelaksanaan Pendidikan Karakter Terhadap Siswa Sekolah Dasar. Jurnal Pendidikan Karakter, 6(2), 156166. https://doi.org/10.21831/jpk.v6i2.12045

Nadjamuddin, A. (2016). Membangun Karakter Anak Lewat Permainan Tradisional Daerah Gorontalo. Tadbir: Jurnal Manajemen Pendidikan Islam, 4(2), 74-79.

Ningsih, E. F., Firzal, Y., \& Aldy, P. (2020). Penerapan prinsip Desain Daniel Libeskind pada Fasilitas Permainan Tradisional Melayu Riau di Pekanbaru. ARTEKS : Jurnal Teknik Arsitektur, 5(2), 219-228. https://doi.org/10.30822/arteks.v5i2.389

Purwaningsih, E. (2006). Permainan Tradisional Anak, Salah Satu Khasanah Budaya yang Perlu Dilestarikan. Jurnal Jantra, 1(1), 40-46.

Rahayu, D., Hamid, S. I., \& Sutini, A. (2018). Peningkatan Keterampilan Sosial Anak Usia Dini Melalui Permainan Tradisional. Cakrawala Dini: Jurnal Pendidikan Anak Usia Dini, 7(2), 1-8. https://doi.org/10.17509/cd.v7i2.10527

Rahayu, S., \& Alber, A. (2019). Nilai-Nilai Budaya dalam Gurindam Tunjuk Ajar Melayu Karya Tenas Effendy. Geram, $7(1)$, 90-100. https://doi.org/10.25299/geram.2019.vol7 (1). 2878

Rasyid, S., Saman, \& Syahrani, A. (2016). Klasifikasi Kosakata Permainan Rakyat Melayu Sambas : Pendekatan Etnolinguistik. Jurnal Bahastra, 75-101.

Susanti, F., Siswati, \& Widodo, P. B. (2010). Pengaruh Permainan Tradisional terhadap Kompetensi Interpersonal dengan Teman Sebaya pada Siswa SD. Jurnal Psikologi Undip, 8(2), 145-155.

Syaharuddin, S., Pramita, D., \& Sirajuddin, S. (2019). Pengenalan Operasi Tambah Kurang Melalui Permainan Congklak Bagi Siswa Sekolah Dasar. JMM (Jurnal Masyarakat Mandiri), 3(1), 01. https://doi.org/10.31764/jmm.v3i1.900
Zafirah, A., Agusti, F. A., Anwar, F., Alvi, A. F., Negeri, U., Dasar, S., ... Ummah, K. (2018). Penanaman Nilai-nilai Karakter terhadap Peserta Didik melalui Permainan Congkak sebagai Media Pembelajaran. Jurnal Pendidikan Karakter, 8(1), 95-104. https://doi.org/10.21831/jpk.v8i1.21678

Zulhafizh, \& Permatasari, S. (2020). Developing Quality of Learning in the Pandemic Covid-19 Through Creative and Critical Thinking Attitudes. JURNAL PAJAR (Pendidikan dan Pengajaran), 4(5), 937949. https://doi.org/10.33578/pjr.v4i5.8080

Zulhafizh, Z. (2020). Orientasi Pelaksanaan Kurikulum Pembelajaran di Tingkat Satuan Pendidikan Menengah Atas: Perspektif Guru. JURNAL PAJAR (Pendidikan dan Pengajaran), 4(2). https://doi.org/10.33578/pjr.v4i2.7943 